\title{
Evaluation of chemical stabilizers for the retention in a mining tailing contaminated soil
}

\author{
C.G. Sáenz-Uribe ${ }^{1}$, M.A. Olmos-Márquez ${ }^{1}$, M.T. Alarcón-Herrera ${ }^{2}$ \& J.M. Ochoa-Rivero ${ }^{3}$ \\ ${ }^{1}$ Universidad Autónoma de Chihuahua, Chihuahua, Chih., Mexico \\ ${ }^{2}$ Centro de Investigación en Materiales Avanzados, SC, Chihuahua, Chih., Mexico \\ ${ }^{3}$ Instituto Nacional de Investigaciones Forestales, Agrícolasy Pecuarias, Aldama, Chih., Mexico
}

\begin{abstract}
This study focused on studying the chemical stabilization of arsenic (As) in mining tail from a contaminated site in the north of Mexico. The main objective was to evaluate the behavior of As solubility in the contaminated soil after its amendment with manganese oxide (cryptomelane) prepared by two different procedures (McKenzie and Gangas). The initial concentration of total As was $2797 \mathrm{mg} \mathrm{kg}^{-1}$ during 10 days of experimentation under controlled conditions; it was found that the reduction of soluble arsenic occurred since the second day using cryptomelane obtained by Gangas procedure.
\end{abstract}

\section{INTRODUCTION}

Contamination of the environment by arsenic (As) from both natural and anthropogenic sources has occurred in many parts of the world and it is nowadays recognized as a global problem (Vodyanitskii, 2009). One of the principal anthropogenic sources for soil contamination by As include the mining of lead and zinc (Stafilov et al., 2010). Mining and metallurgical activities in Chihuahua City have a long story; one of the most recent case is the Avalos smelter, which is located in the southeast of the city and produced lead and zinc from the 1908s until 1993. These wastes contain high contents of heavy metals and metalloids such As, which have caused environmental pollution in the area (Puga et al., 2006). The high cost of traditional soil remediation techniques (excavation and landfilling) and limited resources allocated to remediate contaminated sites prompted the development of alternative techniques that are cost-effective and less disruptive to the environment such as soil stabilization (Mulligan et al., 2001). The objective of this study was to evaluate the effects of As bioavailability in a contaminated soil, after amended with a manganese oxide (cryptomelane), prepared by two different techniques.

\section{METHODS AND EXPERIMENT}

\subsection{Soil selection and As extraction}

The soil collected for this study was taken from the surroundings of Avalos smelter $\left(28^{\circ} 37^{\prime} 17.32^{\prime \prime} \mathrm{N}\right.$, $\left.106^{\circ} 00^{\prime} 12.73^{\prime \prime} \mathrm{W}\right)$. Soil samples were taken at $0.30 \mathrm{~m}$ of depth from six points near to the tailing dam. These soil samples were joined and sieved through a 0.83mm opening sieve (\#20) to remove large particles and provide a homogeneous soil size. For initial concentration of total and soluble As determination, were taken two simple samples (S1 and S2) of $2 \mathrm{~kg}$ in duplicate. For the arsenic determination, the soil samples were acid digested with $\mathrm{HNO}_{3}$ in Teflon ${ }^{\mathrm{TM}}$ containers using a microwave digester CEM model MARS-X®. The extractions of soluble As were performed through two extraction techniques: a) PEC method using glacial acetic acid (PEC), according NOM-053-SEMARNAT1993 and b) ABA modified method, using carbonic acid (ABA), according NOM-141-SEMARNAT-2003. The As extracted material was vacuum filtered with TLPC filters. After that, the samples were analyzed by atomic absorption (AA) according NMX-AA132-SCFI-2016, using $\mathrm{HACH}^{\circledR}$ spectrometer model DR2000 ${ }^{\mathrm{TM}}$.

\subsection{Preparation of chemical stabilizers}

For the chemical stabilization of polluted soil samples, 2 cryptomelane $\left(\mathrm{KMn}_{8} \mathrm{O}_{16}\right)$ stabilizers were prepared. The first was obtained according to the Ganga $(\mathrm{G})$ method (Hettiarachchi \& Pierzynski, 2000). The second method considered was the McKenzie (M) method (McKenzie, 1971); both stabilizers were analyzed by X-ray diffraction in Xpert Phillips MPD ${ }^{\circledR}$ instrument. The surface area was determinate by gas adsorption using nitrogen in analyzer Autosorb ${ }^{\circledR} 6 \mathrm{~B}^{\mathrm{TM}}$ with software for Windows ${ }^{\circledR}$ version 1.16. Stabilization tests with the polluted soil were carried out with $0.75 \mathrm{~g}$ of stabilizing agent in two subsamples with $150 \mathrm{~g}$ of soil (G-S1, G-S2, M-S1 and M-S2).

\section{RESULTS AND DISCUSSION}

\subsection{Soil As concentrations}

The initial concentrations of total and soluble As were similar to the composite samples of contaminated soil 
Table 1. Comparison of initial total As concentrations vs. maximal levels references.

\begin{tabular}{lllllll}
\hline & & & & $\begin{array}{l}\text { Reference } \\
\text { for } \\
\text { agricultural/ } \\
\text { residential }\end{array}$ & $\begin{array}{l}\text { Reference } \\
\text { for } \\
\text { industrial } \\
\text { land use }\end{array}$ & land use \\
Sample & S1 & S2 & Avg & land \\
\hline $\begin{array}{l}\text { Total As } \\
\left(\mathrm{mg} \mathrm{kg}^{-1}\right)\end{array}$ & 2842.5 & 2750.8 & 2796.6 & 22 & 260 \\
$\begin{array}{l}\text { Soluble As } \\
\left(\mu \mathrm{g} \mathrm{L}^{-1}\right)\end{array}$ & 10.4 & 10.7 & 10.5 & & - \\
\hline
\end{tabular}

${ }^{1}$ NOM-147-SEMARNAT/SSA1-2003.

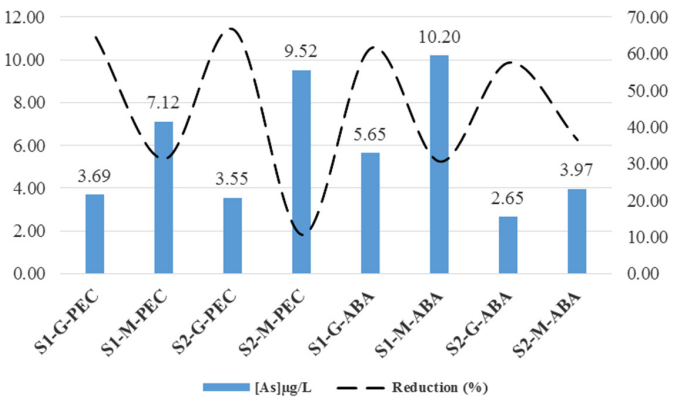

Figure 1. As concentration in soil samples, after the chemical stabilization.

(S1 and S2). The results showed that total As concentrations in soil was above the maximal levels allowed by Mexican regulations for industrial land use. Table 1 shows the average concentrations of total and soluble As and its normative references.

\subsection{Chemical stabilizers performance}

About the properties of the chemical stabilizers, $\mathrm{X}$-ray diffraction indicated that the peaks obtained by the process recommended by Ganga stabilizer $(G)$ tied perfectly with the graphs from X'pert Highscore software ${ }^{\mathrm{TM}}$, with a surface area of $130.37 \mathrm{~m}^{2} \mathrm{~g}^{-1}$. On the other hand, McKenzie stabilizer (M) has a surface area of $302.22 \mathrm{~m}^{2} \mathrm{~g}^{-1}$, but the peaks shown had not defined in different sections on the graph, which indicate that the compound did not crystallize. In order to compare the efficiency of the stabilizers $\mathrm{G}$ and $\mathrm{M}$, they were treated with ABA modified and PEC methods of extraction. For soluble As extractions, the method PEC and Ganga stabilizer were significant more effective. Figure 1 shows the values and percentage reduction in the concentration of soluble As.

\subsection{Stabilization time}

It was obtained the velocity of stabilization through $\mathrm{G}$ stabilizer during 10 days.

The greatest total As reduction was detected after 4 days, with a reduction of $38.86 \%$. The soluble As
Table 2. Concentrations of total and soluble As and its reduce percentage after 10 days of stabilization time.

\begin{tabular}{llllll}
\hline & Total As & & \multicolumn{2}{l}{ Soluble As } \\
\cline { 2 - 3 } \cline { 5 - 5 } $\begin{array}{l}\text { Time } \\
\text { days }\end{array}$ & $\left(\mathrm{mg} \mathrm{kg}^{-1}\right)$ & $\begin{array}{l}\% \\
\text { reduction }\end{array}$ & & $\left(\mu \mathrm{g} \mathrm{L}^{-1}\right)$ & $\begin{array}{l}\% \\
\text { reduction }\end{array}$ \\
\hline 2 & 2109.66 & 24.56 & & N.D. & 100 \\
4 & 1709.67 & 38.86 & & N.D. & 100 \\
6 & 2005.92 & 28.27 & & N.D. & 100 \\
8 & 2055.03 & 26.51 & & N.D. & 100 \\
10 & 2342.06 & 16.25 & & N.D. & 100 \\
Avg & 2044.47 & 26.89 & & N.D. & 100 \\
\hline
\end{tabular}

N.D.: Not detected.

was reduced to no detected values (ND) since the 2nd day; that indicates that the contaminated soil can be stabilized in less than 2 days. Table 2 shows the values of total and soluble As. Additional analyzes will be carried out to determine the average stabilization time.

\section{CONCLUSIONS}

The stabilization that gave the highest percentage of retention of arsenic and conversion of soluble arsenic to insoluble was using the Ganga stabilizer $(\mathrm{G})$, with the technique of extraction PEC.

\section{ACKNOWLEDGEMENTS}

National Council Science and Technology (CONACYT) financially supported this work, within the program Attention to National Problems.

\section{REFERENCES}

Hettiarachchi, G.M. \& Pierzynski G.M. 2000. The use of phosphorus and other soil amendments for in situ stabilization of soil lead. Proc. of the 2000 Conference on Hazardous Waste Research, pp. 125-133.

McKenzie, R.M. 1971. The synthesis of birnessite, cryptomelane, and some other oxides and hydroxides of manganese. Mineralogical Mag. 38(296):493-502.

Mulligan, C.N., Yong, R.N. \& Gibbs, B.F. 2001. Remediation technologies for metal-contaminated soils and groundwater: an evaluation. Eng. Geol. 60(1-4):193-207.

Puga, S., Sosa, M., Lebgue, T., Quintana, C. \& Campos, A. 2006. Contaminación por metales pesados en suelo provocada por la industria minera. Ecol. Apl. 5(1-2): 149-155.

Stafilov, T., Šajn, R., Pančevski, Z., Boev, B., Frontasyeva, M.V. \& Strelkova, L.P. 2010. Heavy metal contamination of surface soils around a lead and zinc smelter in the Republic of Macedonia. J. Hazard. Mater. 175(1-3): 896-914.

Vodyanitskii, Y.N. 2009. Chromium and arsenic in contaminated soils (review of publications). Eurasian Soil Sci. 42(5): 507-515. 


\title{
Treatment of low-level As contaminated excavated soils using ZVI amendment followed by magnetic retrieval
}

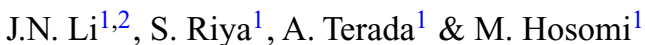 \\ ${ }^{1}$ Department of Chemical Engineering, Tokyo University of Agriculture and Technology, Tokyo, Japan \\ ${ }^{2}$ Research Fellow of Japan Society for the Promotion of Science, Tokyo, Japan
}

\begin{abstract}
This study investigates the remediation of low-level As contaminated excavated soils from construction projects by ZVI amendment followed by magnetic retrieval. A case study was conducted with an alkaline excavated soil (total As only $7.5 \mathrm{mg} \mathrm{kg}^{-1}$ ). The remediation efficiency was assessed using sequential leaching tests. The results showed ZVI amendment ( $1 \% \mathrm{ZVI}$ and $0.5 \mathrm{~mL} \mathrm{~kg}^{-1} \mathrm{H}_{2} \mathrm{SO}_{4}$ of soil) followed by magnetic retrieval could significantly decrease water-leachable As (from $33 \mu \mathrm{g} \mathrm{L}^{-1}$ to $<3 \mu \mathrm{g} \mathrm{L}^{-1}$ ), also the potential leachability of As in this excavated soil. These initial results indicate that this treatment could be developed for the efficient remediation of low-level As contaminated excavated soils.
\end{abstract}

\section{INTRODUCTION}

In Japan, excavated soils with low-level As obtained from construction projects during city development have been of great concern because in many cases the water-leachable As is higher than the environment standard (Soil Leachate Standard in Soil Contamination Countermeasures Law of Japan, $\left.10 \mu \mathrm{g} \mathrm{L}^{-1}\right)(\mathrm{Li}$ et al., 2016, 2017). Now water washing is usually used for the remediation of As-contaminated soils, after which the large soil grains can be reused immediately while the fine soil grains contain high levels of As need to be further treated. After washing, the fine soil grains are more like "sludge" and they are usually treated in disposal sites, which will greatly increase the transportation cost and the load of disposal sites. Hence, the development a cost-effective disposal system to treat low-level As-contaminated excavated soils is urgently needed. The objective of this study was to probe the effectiveness of the zero valent iron (ZVI) amendment followed by magnetic retrieval for remediation of low-level As contaminated excavated soils.

\section{MATERIALS AND METHODS}

\subsection{Soil sample and ZVI product}

The excavated soil was obtained from one construction project in Tokyo, Japan. The sample was air-dried, crushed and sieved through a 2-mm opening mesh. Soil moisture content was $32.5 \%$; soil pH was 9.0 (soil to water ratio; $1: 10$ ); total As was $7.5 \pm 0.13 \mathrm{mg} \mathrm{kg}^{-1}$. The ZVI product was obtained from DOWA ECOSYSTEM, Japan. The Fe content was $940 \pm 7.4 \mathrm{~g} \mathrm{~kg}^{-1}$; the As content was $13.4 \pm 0.5 \mathrm{mg} \mathrm{kg}^{-1}$.

\subsection{Soil treatment}

Before amendment experiment, water content of the soil was adjusted to $15 \%$ using deionized water. This
Table 1. Different soil treatments.

\begin{tabular}{ll}
\hline Test & Description \\
\hline T1 & Original soil (Control 1) \\
T2 & No ZVI; No $\mathrm{H}_{2} \mathrm{SO}_{4}($ Control 2) \\
T3 & No ZVI; Add $\mathrm{H}_{2} \mathrm{SO}_{4}\left(0.5 \mathrm{~mL} \mathrm{~kg}^{-1}\right.$ of soil $)$ \\
T4 & Add ZVI $\left(10 \mathrm{~g} \mathrm{~kg}^{-1}\right) ; \mathrm{No} \mathrm{H}_{2} \mathrm{SO}_{4}$ \\
T5 & Add ZVI $\left(10 \mathrm{~g} \mathrm{~kg}^{-1}\right) ; \mathrm{Add} \mathrm{H}_{2} \mathrm{SO}_{4}\left(0.5 \mathrm{~mL} \mathrm{~kg}^{-1}\right)$ \\
\hline
\end{tabular}

ZVI and $\mathrm{H}_{2} \mathrm{SO}_{4}$ were added on the basis of dry mass of soil.

water content is very low and avoids producing sludge during treatment process. The detailed information about different soil treatments was shown in Table 1. In all treatments, the samples were agitated intensely for $15 \mathrm{~min}$ and then air-dried at room temperature. For magnetic retrieval, two steps were conducted: (1) a rectangular magnet was held in contact with the treated soils' surfaces and moved horizontally back and forth until no solids could be pulled out of the soils. The remaining soils were considered as non-magnetic (NMS); (2) the mixtures obtained at previous step were further magnetically-separated to retrieve ZVI powders only (post-test ZVI); and the remaining soils after this step were considered as weakly-magnetic (WMS). The As and other elements in different parts were digested using a strong acid $\left(\mathrm{HClO}_{4}-\mathrm{HNO}_{3}-\mathrm{HF}\right)$ digestion method.

\subsection{Sequential leaching tests (SLT)}

The parameters of each step of SLT were generally in accord with the standard leaching test in Japan. $3 \mathrm{~g}$ of sample was mixed with $30 \mathrm{~mL}$ deionized water in a $50 \mathrm{~mL}$ polypropylene centrifuge tube. The tubes were shaken using a lateral-reciprocating shaker at $200 \mathrm{rpm}$ for $6 \mathrm{~h}$ at room temperature, after which the $\mathrm{pH}$ values of the suspensions were measured immediately. The suspensions were then centrifuged at about $6000 \mathrm{rpm}$ 